\title{
Proteomic analysis of NGF-induced transdifferentiation of adrenal medullary cells
}

\author{
CHENG-PING HU ${ }^{1}$, XIAO-RONG WU ${ }^{2}$, QIU-GEN LI ${ }^{3}$, ZUO-WEI SUN ${ }^{3}$, \\ AI-PING WANG ${ }^{3}$, JUN-TAO FENG ${ }^{1}$ and $\mathrm{JUN}^{\mathrm{WANG}}{ }^{3}$ \\ ${ }^{1}$ Department of Respiratory Medicine, Central South University, Xiangya Hospital, Changsha, \\ Hunan; ${ }^{2}$ Department of Ophthalmology, The First Affiliated Hospital, Nanchang University; \\ ${ }^{3}$ Second Department of Respiratory Disease, Jiangxi Provincial People's Hospital, Nanchang, Jiangxi, P.R. China
}

Received February 18, 2013; Accepted April 25, 2013

DOI: $10.3892 /$ ijmm.2013.1387

\begin{abstract}
Nerve growth factor (NGF) is a polypeptide growth factor with specific trophic function in nerve cells and was initially investigated for its role as a key player in the regulation of peripheral innervations. The aim of this study was to examine the NGF-induced transdifferentiation of adrenal medullary cells, and to screen the major candidate differentially expressed proteins involved in the transdifferentiation. NGF was used to treat primary cultures of neonatal calf adrenal medullary cells and the effects of transdifferentiation were determined in association with cellular morphology, ultrastructure and changes in endocrine function. Differentially expressed proteins were screened and identified through two-dimensional gel electrophoresis and mass spectrometry. The protein spots showing differential expression were verified by western blot analysis. We observed neurite outgrowth in the adrenal medullary cells treated with NGF under a phase contrast microscope. Ultrastructure analysis revealed that there were rich drumsticklike and villiform processes on the cell membranes and vesicles were formed near the cell membranes. The cytoplasm was rich in mitochondria and the secretion of epinephrine was decreased. Two-dimensional gel electrophoresis revealed that among the differentially expressed proteins, 48 protein spots showed an upregulated expression and 37 protein spots showed a downregulated expression, and no 'all-or-none' spots with significant differences in expression were found. Fourteen protein spots with an upregulated expression and 6 with a downregulated expression were randomly selected for identification by mass spectrometry. Western blot analysis revealed that ras homologus oncogene (Rho) GDP dissociation inhibitor $\alpha$ (RhoGDI $\alpha$ ) protein expression was significantly downregulated and periph-
\end{abstract}

Correspondence to: Dr Jun Wang, Second Department of Respiratory Disease, Jiangxi Provincial People's Hospital, Nanchang, Jiangxi 330000, P.R. China

E-mail:wangjj27@163.com

Key words: transdifferentiation, adrenal medullary cells, nerve growth factor, proteomics erin protein expression was significantly upregulated. In brief, our data demonstrate that NGF can induce the differentiation of adrenal medullary cells into neurons, and that RhoGDI $\alpha$ and peripherin may play important roles in this process.

\section{Introduction}

Nerve growth factor (NGF) is a polypeptide growth factor with specific trophic function in nerve cells, which plays an important role in the regulation of several processes, including neuronal survival, proliferation, differentiation, neurite growth and neurotransmission (1).

Adrenal medullary cells are derived from the neural crest ectoderm and are connected with the sympathetic division of the autonomic nervous system; in a glucocorticoid microenvironment, they invade the adrenal primordium and then develop into medullary cells with endocrine functions. Therefore, adrenal medullary cells and sympathetic neurons bear many similarities, such as synthesizing, storing and releasing catecholamines and neuropeptides (2). Similarly, mature and immature adrenal medullary cells have a pluripotent differentiation capacity in varying degrees $(3,4)$. It has been verified by in vivo $(5,6)$ and in vitro $(3,7,8)$ studies that in a environment rich in NGF, adrenal medullary cells can transform from an endocrine phenotype into a neuronal one and their endocrine function simultaneously changes with the transformation.

The aim of this study was to explore the NGF-induced transdifferentiation of adrenal medullarry cells into neurons based on the culture of the primary adrenal medullary cells. Using proteomics technology, we screened the major candidate differentially expressed proteins involved in the transdifferentiation. Our results may provide new clues to further illustrate the signal transduction process of NGF-regulated adrenal medullary cell differentiation.

\section{Materials and methods}

Separation and primary culture of adrenal medullary cells. Healthy newborn calf adrenal tissues were obtained from the Cell Center of Xiangya Medical College of Central South University, Changsha, China. The bilateral adrenal glands were removed under aseptic conditions, and were immediately 
placed into cleaning fluid with 3 antibiotics $(100 \mu / \mathrm{ml}$ penicillin, $100 \mu \mathrm{g} / \mathrm{ml}$ streptomycin and $50 \mu \mathrm{g} / \mathrm{ml}$ gentamicin) and washed 3 times. The adrenal glands were cut longitudinally into 2 halves and the external cortexes were cut off. Separated small pieces of medulla were collected into the mouth of a sterile test tube. Small pieces of medulla were cut into pieces with a sterile curved scissors; then $4-5 \mathrm{ml} 0.1 \%$ collagenase were added and the sections were placed into a $37^{\circ} \mathrm{C}$ water bath and allowed to dissolve for 45-60 min. The tubes were gently vibrated during the dissolution process to mix the tissue completely with digestive juice. After the dissolution, the filtrate was filtered through a 200-mesh sieve and collected with a sterile centrifuge tube. Subsequently, 5\% BSA D-Hanks solution was added followed by centrifugtion for $5 \mathrm{~min}$ at 50-100 rpm. The fog-like supernatant was carefully absorbed and abandoned. Subsequently, $1 \%$ D-Hanks solution was added to the precipitate. D-Hanks solution containing $5 \%$ BSA with twice the original volume of cell suspension was added to another sterile centrifuge tube, and the cell suspension was gently added onto the surface of the solution. Cellular sediment was detected at the bottom of the tube after the solution was centrifuged at $100 \mathrm{rpm}$ for $5 \mathrm{~min}$. The supernatant was carefully absorbed and abandoned. Cells were washed with $1 \%$ BSA D-Hanks solution once and $10 \%$ of FBS-DMEM complete medium was added. Cells were implanted in a 50-ml glass cell culture bottle and a small number was obtained for cell counting. The cells were then placed in an incubator at $37^{\circ} \mathrm{C}$ with $5 \% \mathrm{CO}_{2}$ and cultured in a $5 \% \mathrm{CO}_{2}$ and $95 \%$ air atmosphere. Two hours later, when nonadrenal chromaffin cells adhered to the wall, the supernatant was gently absorbed and moved into a culture bottle, and the solution was changed once every 2 days $(9,10)$.

Electron microscopic identification of adrenal medullary cells. Cells cultured in the culture bottle were dissolved and collected with $0.25 \%$ of trypsin and $0.01 \%$ of EDTA, then pre-fixed with $2.5 \%$ of glutaraldehyde, rinsed with $0.01 \mathrm{M}$ PBS, post-fixed with $1 \%$ of osmium tetroxide, and then rinsed with $0.01 \mathrm{M} \mathrm{PBS}$, stepwise dehydrated with acetoneacid (50, 70, 90 and 100\%), soaked with EPON 812 epoxy resin embedding medium and $100 \%$ acetone in ratio of $1: 1$, then soaked and embed with pure embedding medium. The blocks were trimmed on a pyramitome, sliced using a ultramicrotome, and then double staining was performed using uranyl acetate and lead nitrate. Finally, the ultrastructure of the adrenal medullary cells was observed under an H-600 transmission electron microscope and distinctive chromaffin granules with homogeneous density were noted in the cytoplasm of normal adrenal chromaffin cells.

Cell morphology and endocrine functional changes with NGF intervention. The isolated adrenal medullary cells obtained using the digestion method were equivalently $\left(1 \times 10^{6}\right)$ divided into the control group and the NGF-treated group, which were inoculated directly in culture flasks for culture at $37^{\circ} \mathrm{C}$ in a $5 \%$ $\mathrm{CO}_{2}$ incubator. In the NGF-treated group, the adrenal medullary cells were co-cultured with NGF $(100 \mathrm{ng} / \mathrm{ml})$ as previously described (11) and the final concentration was maintained at $10^{-4} \mathrm{mM}$. Equivalent amounts of PBS were added to the control group. Morphological changes were observed under a phase contrast microscope, and the medium was changed every 2 days. Cell culture supernatant was collected on the 1st, 2nd, 4th and 6th day. Epinephrine concentration in the culture supernatant was detected by enzyme-linked immunosorbent assay (ELISA).

Observations of cell ultrastructural changes following treatment with NGF under an electron microscope. Primary cultures of adrenal medullary cells were collected 7 days after treatment with NGF, fixed in $2.5 \%$ glutaraldehyde, rinsed with $0.01 \mathrm{M}$ PBS, post-fixed with osmium tetroxide, rinsed with 0.01 M PBS, stepwise dehydrated with pyruvic acid (50, 70, 90 and 100\%), soaked with EPON 812 epoxy resin embedding medium and $100 \%$ acetone in ratio of $1: 1$, then soaked and embed with pure embedding medium. The blocks were trimmed on a pyramitome, sliced using a ultramicrotome, and then double staining was performed using uranyl acetate and lead nitrate. Finally, the ultrastructure of the adrenal medullary cells was observed under an H-600 transmission electron microscope.

Two-dimensional gel electrophoresis, gel image analysis and mass spectrum analysis. Adrenal medullary cells were collected 7 days following treatment with NGF and the supernatant was removed by centrifugation and washed 3 times with $0.9 \% \mathrm{NaCl}$ solution. The supernatant was removed by a brief centrifugation at $10,000 \mathrm{rpm}$. Subsequently, $400 \mu \mathrm{l}$ of tissue lysate were added to these cells ( $7 \mathrm{M}$ urea, $2 \mathrm{M}$ thiourea, $4 \%$ CHAPS, $65 \mathrm{mM}$ DTT, 40 mM Tris, 0.5 mM EDTA, 2\% NP-40, 1\% Triton X-100, $5 \mathrm{mM}$ PMSF and $2 \%$ pharmalyte) and mixed using a pipette tip. The sequence of freezing and thawing was repeated for a total of 3 times in liquid nitrogen tank. It was allowed to stand for $60 \mathrm{~min}$ in a $37^{\circ} \mathrm{C}$ water bath and centrifuged for $30 \mathrm{~min}$ at $12,000 \mathrm{rpm}$. The supernatant was collected in another 2 Eppendorf tubes. Attention should be paid not to draw the lower cell debris sediment. Five microliters sample of each specimens were retained for the measurement of the concentration. The extracted protein samples were stored at $-70^{\circ} \mathrm{C}$. Protein concentrations were measured using the 2D Quant protein quantification kit (2D Quant kit, Amersham Biosciences, Uppsala, Sweden) for two-dimensional gel electrophoresis analysis.

Solid phase Ph gradient - SDS two-dimensional gel electrophoresis. The operating steps were carried out according to the IPGphor isoelectric focusing system guide. The required sample volume was calculated based on the concentration of cellular proteins. The protein sample level of each rubber stripe was $800 \mu \mathrm{g}$ and appropriate amount of hydration liquid was added (8 M urea, 2\% CHAPS, $40 \mathrm{mM}$ Tris, $18 \mathrm{mM}$ of DTT, $0.5 \%$ IPG buffer PH3-10L, a trace of bromophenol blue) and thoroughly mixed. The sample volume was $450 \mu \mathrm{l}$ and it was added to the IPG gel tank (holder). Automatic IPG dry strip hydration and isoelectric focusing were performed at $20^{\circ} \mathrm{C}$, the total voltage time product was $69,990 \mathrm{~V} / \mathrm{h}$, wherein $30 \mathrm{~V}$ low voltage hydrated for $13 \mathrm{~h}$, then $100 \mathrm{~V}$ for $1 \mathrm{~h}(100 \mathrm{Vhr})$, $500 \mathrm{~V}$ for $1 \mathrm{~h}(500 \mathrm{Vhr}), 1,000 \mathrm{~V}$ for $1 \mathrm{~h}(1,000 \mathrm{Vhr})$, and finally stabilized at $8,000 \mathrm{~V}$ for $8.5 \mathrm{~h}$ for isoelectric focusing. After isoelectric focusing, the strips were placed in the balance tubes with the gel side facing up. Ten milliliters of balanced salt solution A and $10 \mathrm{ml}$ of balanced salt solution B were poured into the tubes successively for a two-step balance. Shaking was carried out on a rocker with each balance for $15 \mathrm{~min}$. After equilibration, the IPG strips were transferred to the upper end of a $12.5 \%$ SDS-PAGE gel, and then placed in the Ettan 
DALT II vertical electrophoresis tank (Amersham Biosciences) for a second vertical electrophoresis. After electrophoresis, the two-dimensional polyacrylamide gel electrophoresis (2-DE) gel was stained with coomassie blue and the experiment was repeated 3 times. Coomassie blue-stained gels were scanned using an ImageScanner gel scanner (Amersham Biosciences) and LabScan scanning software (Applied Biosystems, Foster City, CA, USA) to obtain images. The differences in the two-dimensional electrophoresis pattern of the control group and NGF-treated group were analyzed using PDQuest 2-DE software (Bio-Rad, Hercules, CA, USA). The protein spots showing a $>2$-fold change in expression were selected for mass spectrometry analysis.

Differential protein expression patterns were obtained by mass spectrometry. The protein spots of interest showing differential expression were cut into Eppendorf tubes, decolorated for $30 \mathrm{~min}$ with $50 \%$ acetonitrile and $100 \mathrm{mM}$ ammonium bicarbonate. They were then dehydrated, frozen and drained; then $10 \mu \mathrm{l}$ TPCK trypsin $(0.1 \mathrm{mg} / \mathrm{l})$ was added followed by imbibition on ice for $60 \mathrm{~min}$, followed by enzymolysis at $37^{\circ} \mathrm{C}$ for $12 \mathrm{~h} ; 30 \mu \mathrm{l}$ extract was then used (100\% acetonitrile:5\% formic acid, 1:1) for extraction for $60 \mathrm{~min}$; extraction was repeated one more time. The extract was collected in $0.5 \mathrm{ml}$ Eppendorf tubes, which was frozen and concentrated to be completely lyophilized. The prepared samples were analyzed by electrospray ionization quadrupole time-of-flight (ESI-Q-TOF) electrospray ionization tandem mass spectrometry. All measurements were performed in the positive ion mode with nitrogen as the atomizing gas and argon as the collision gas. The source temperature was $80^{\circ} \mathrm{C}$, the cone voltage was $50 \mathrm{~V}$, TOF acceleration voltage was $0.2 \mathrm{kV}$ and micro-channel plate (MCP) detector voltage was $2.7 \mathrm{kV}$. When liquid chromatography (LC)-ESI-MS/MS automatic analysis was being performed, the capillary voltage was $3,000 \mathrm{~V}$. The measurement results were presented in the form of a peak list document. The NCBI database was retrieved using Mascot software for the identification of proteins.

Verification of protein spots showing differential expression levels by western blot analysis. The adrenal medullary cells which were treated with NGF for 2, 4 and 6 days were collected and sufficiently washed with PBS. They were then added to the pre-cooled lysis buffer solution (50 mM Tris $\mathrm{pH}$ of 8.0, $150 \mathrm{mM}$ $\mathrm{NaCl}, 0.1 \%$ SDS, $1 \%$ Triton $\mathrm{X}-100,0.5 \%$ sodium deoxycholate, $1 \mathrm{mM}$ PMSF, $5 \mu \mathrm{g} / 1$ aprotinin, $5 \mu \mathrm{g} / 1$ leupeptin), then vortex mixed. After cracking on ice for $30 \mathrm{~min}$, they were removed by centrifugation at $12,000 \mathrm{x} \mathrm{g}$ for $10 \mathrm{~min}$. The supernatant was the cell total protein. When the protein concentration was determined, $30 \mu \mathrm{g}$ [ras homologus oncogene (Rho) GDP dissociation inhibitor $\alpha$ (RhoGDI $\alpha$ ) detected] or $100 \mu \mathrm{g}$ (peripherin detected) total proteins were absorbed for the separation of $12.5 \%$ SDS-PAGE. The proteins were transferred onto a nitrocellulose membrane. The blotting membrane was blocked at room temperature for $1 \mathrm{~h}$ with $5 \%$ skim milk. Dilution of the first antibody (RhoGDI $\alpha$ antibody 1:600 dilution, peripherin antibody $1: 150$ dilution, $\beta$-actin antibody 1:2,000 dilution) was added to the hybridization bags and incubated overnight at $4^{\circ} \mathrm{C}$ in an orbital shaker platform (generally for 18-20 h). Horseradish peroxidase (HRP) was added to hybridization bags to label goat anti-rabbit (1:10,000 dilution) and incubated at $37^{\circ} \mathrm{C}$ in an orbital shaker platform for $1 \mathrm{~h}$, then washed
3 times with PBS. ECL reagents were used for luminescence and development. $\beta$-actin was served as an internal reference and the experiment was repeated 3 times.

Statistical analysis. The results are presented as the means \pm standard deviation. The data were obtained by univariate analysis of variance using SPSS11.0 statistical software. A comparison between the untreated and the group treated with NGF was performed by repeated measures analysis of variance and a P-value $<0.05$ was considered to indicate a statistically significant difference.

\section{Results}

Identification of adrenal medullary cells. As observed under an electron microscope, there were characteristic evenly distributed light black chromaffin cell secretory granules (Fig. 1A) in the cytoplasm of the adrenal medullary cells; thus, chromaffin cells of the adrenal medulla were confirmed.

Effect of NGF on the biological behavior of adrenal medullary cells. Under a phase contrast microscope, the freshly isolated adrenal medullary cells were round in shape, while in the control group, the cells remained round for 2 days; after 4 days a small number of cells transformed into bipolar-or short rodlike shaped cells or cells with a club-like shape (Fig. 1B). In the NGF group, 2 days after the cells were treated with NGF, filamentous or mesh protrusions were noted in the adrenal medullary cells and the length of the protrusions gradually increased with time (Fig. 1C).

Under an electron microscope, the surface of the adrenal medulla normal cell membrane was smooth and the mitochondria were clear without vesicles. After the cells were treated with NGF, a high number of club-like shaped cells and villi were observed on the surface of cell membrane; we also observed the formation of small vesicles near the cell membrane and the cytoplasm was rich in mitochondria but obscure in structure; part of the ridges were lost, as well as part of the endoplasmic reticulum and vacuoles in some of the cytoplasms (Fig. 1D).

Epinephrine concentration changes before and after treatment with NGF. The total effect of adrenaline after treatment with NGF was $\mathrm{F}=10.338, \mathrm{P}=0.018$ and it was confirmed that the adrenaline concentrations were significantly lower after treatment with NGF (Table I).

Two-dimensional gel electrophoresis pattern before and after treatment of adrenal medullary cells with NGF. The same batch of total proteins of adrenal medullary cell samples treated with NGF with the sample volume of $1,000 \mu \mathrm{g}$ were assayed repeatedly 3 times. The 3 two-dimensional gel electrophoresis patterns were quite similar. An ImageScanner was used to obtain 2 images and they were then analyzed using PDQuest7.1.0 software (Bio-Rad). The average protein spots in the adrenal medullary cell group and NGF-treated group were $752 \pm 34$ and $693 \pm 46$, respectively and the matching rate reached $92.1 \%$. Subsequently, 50 protein spots from 3 of the same sample gel pattenrs were randomly selected with mutual matching characteristics and clear distinctions. A point near the center was selected as the origin and the reference gel (Marker) 

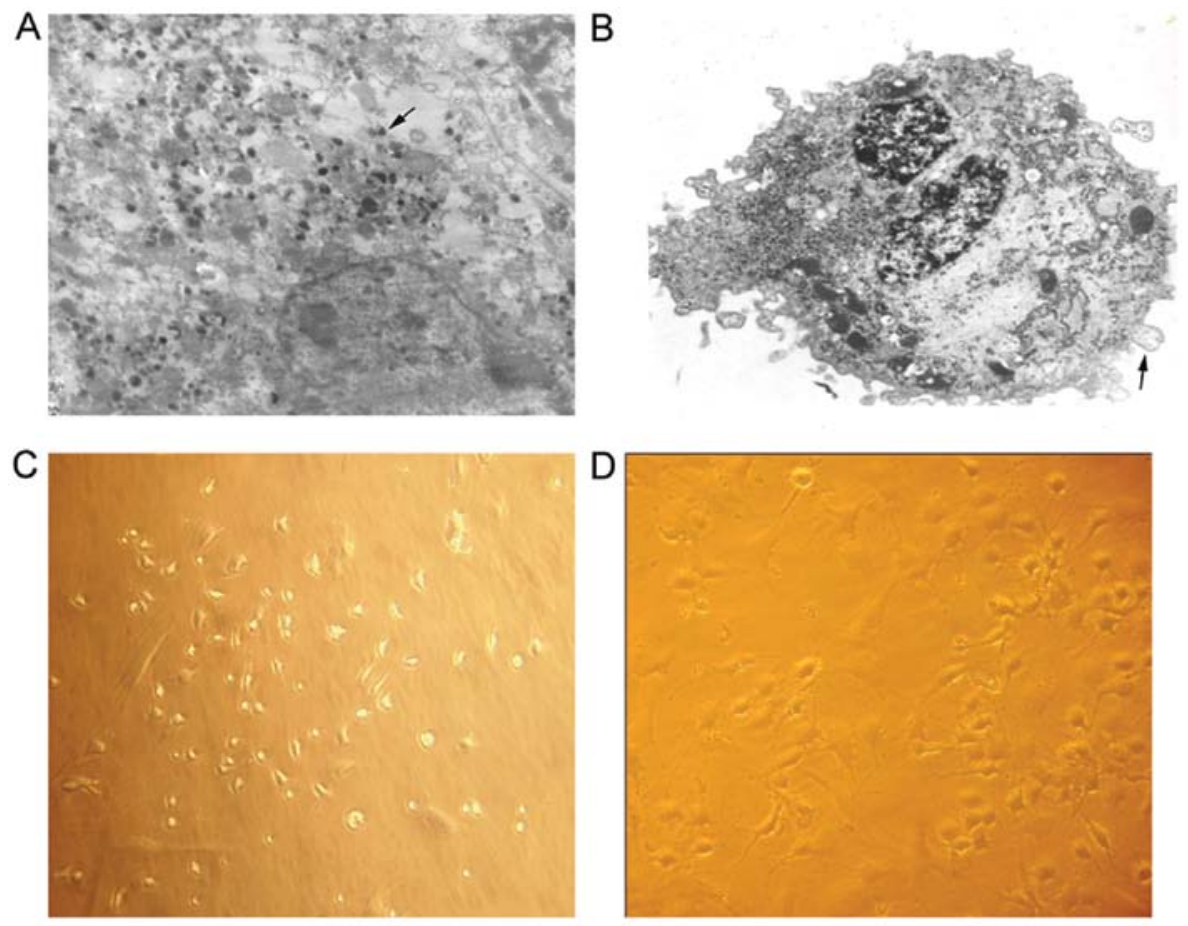

Figure 1. Electron microscopic identification of adrenal medullary cells. (A) As revealed by an electron microscope (x10,000), there were characteristic evenly distributed light black chromaffin cell secretory granules (arrow). (B) Treatment with nerve growth factor (NGF) altered the ultrastructure of the adrenal medullary cells, as observed under an electron microscope $(x 6,000)$; the freshly isolated adrenal medullary cells were round in shape, while in the control group, they remained round at 2 days and at 4 days, a small number of cells transformed into bipolar- or short rod-like shaped cells or cells with a club-like shape (arrow). (C) Primary cultures of adrenal medullary cell under a phase contrast microscope (x400); 2 days after the cells were treated with NGF, filamentous or mesh protrusions were noted in the cells and the length of the protrusions gradually increased with time. (D) Ultrastructure of adrenal medullary cells following treatment with NGF under a phase contrast microscope (x400). Following treatment with NGF, a high number of club-like shaped cells and villi were observed on the surface of cell membrane, as well as the formation of small vesicles near the cell membrane with a cytoplasm rich in mitochondria but with an obscure structure, with a loss of part of the ridges, part of the endoplasmic reticulum expansion and vacuoles in some cytoplasms.

Table I. Epinephrine concentration changes before and after treatment with nerve growth factor (NGF).

\begin{tabular}{|c|c|c|}
\hline & $\begin{array}{l}\text { Before treatment } \\
\qquad(\mathrm{ng} / \mathrm{ml})\end{array}$ & $\begin{array}{l}\text { After treatment } \\
\qquad(\mathrm{ng} / \mathrm{ml})\end{array}$ \\
\hline Day 2 & $10.04 \pm 0.53$ & $9.44 \pm 1.26$ \\
\hline Day 4 & $9.78 \pm 1.08$ & $7.14 \pm 0.92$ \\
\hline Day 6 & $9.62 \pm 1.32$ & $7.0 \pm 1.35$ \\
\hline F-value & \multicolumn{2}{|c|}{$\mathrm{F}=10.338$} \\
\hline P-value & \multicolumn{2}{|c|}{$\mathrm{P}=0.018$} \\
\hline
\end{tabular}

was taken as the reference position. The measured deviation of the protein spots among the different gels in the direction of the isoelectric point was $0.857 \pm 0.214 \mathrm{~mm}$ and the measured deviation in the direction molecular weight was $0.912 \pm 0.235 \mathrm{~mm}$; therefore, two-dimensional gel electrophoresis patterns in the adrenal medullary cell group and NGF-treated group with higher resolution and better repeatability were obtained. The two-dimensional gel electrophoresis patterns are shown in Fig. 2.

Separation and identification of protein spots showing differential expression. Based on the better repeatability and comparability obtained, we used PDQuest software to analyze the differentially expressed proteins between the 2 groups. Protein spots showing differential expression were referred as the point at which the expression level differed by $>2$ fold and the 3 electrophoretic patterns revealed the same changes. Forty-eight spots showed an upregulated expression and 37 spots showed a downregulated expression in the NGF-treated group and no 'all-or-none' spots with significant differences in expression were found. Fourteen protein spots showing an upregulated expression and 6 proteins spots showing a downregulated expression within the above scope were randomly selected for identification by matrix-assisted laser desorption/ionization-time-of-flight mass spectrometry (MALDI-TOF-MS).

Twenty protein spots showing a $>2$ fold change in expression were selected from the gel. After the identification and analysis by MALDI-TOF, Mascot was used to query MSDB or NCBInr database. The search results were comprehensively evaluated by Mascot scoring, the number of matching segments and the coverage rate. A total of 20 protein spots were identified by mass spectrometry and 17 good peptide mass fingerprintings were obtained, in which point 1,9 and 16 had no results. Table II shows the obtained matched conditions of the peptide fragments of the protein spots with differential expression through identification, expression after treatment with NGF, protein name, molecular weight and the coverage rate of the isoelectric point. Figs. 3 and 4 show the peptide mass fingerprintings of differential protein spots 10 and 19 obtained by identification through MALDI-TOF-MS. 
A

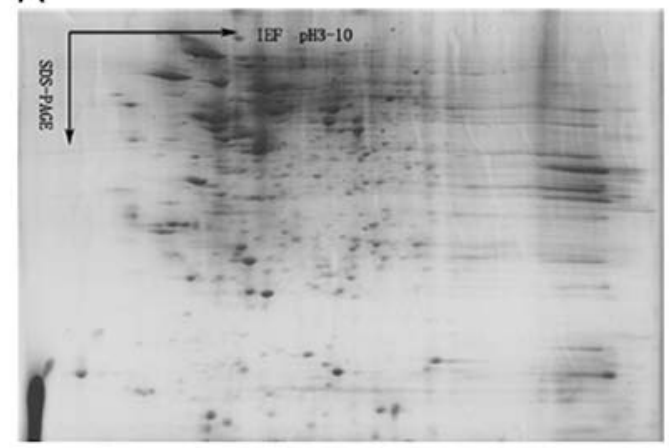

B

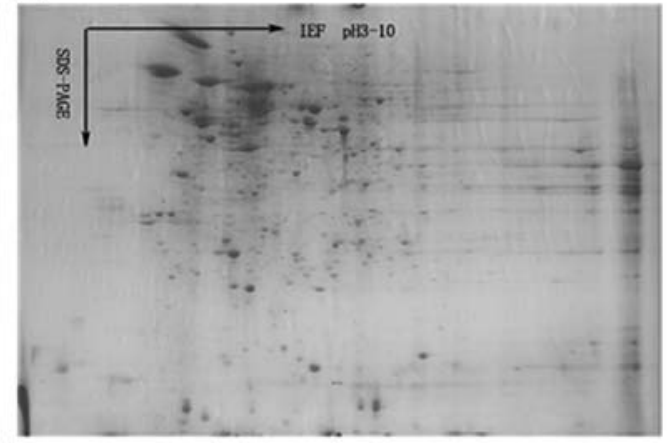

Figure 2. Results of two-dimensional gel electrophoresis, gel image analysis. (A) Two-dimensional gel electrophoresis pattern before adrenal medullary cells were treated with nerve growth factor (NGF). (B) Two-dimensional gel electrophoresis pattern after the adrenal medullary cells wre treated with NGF.

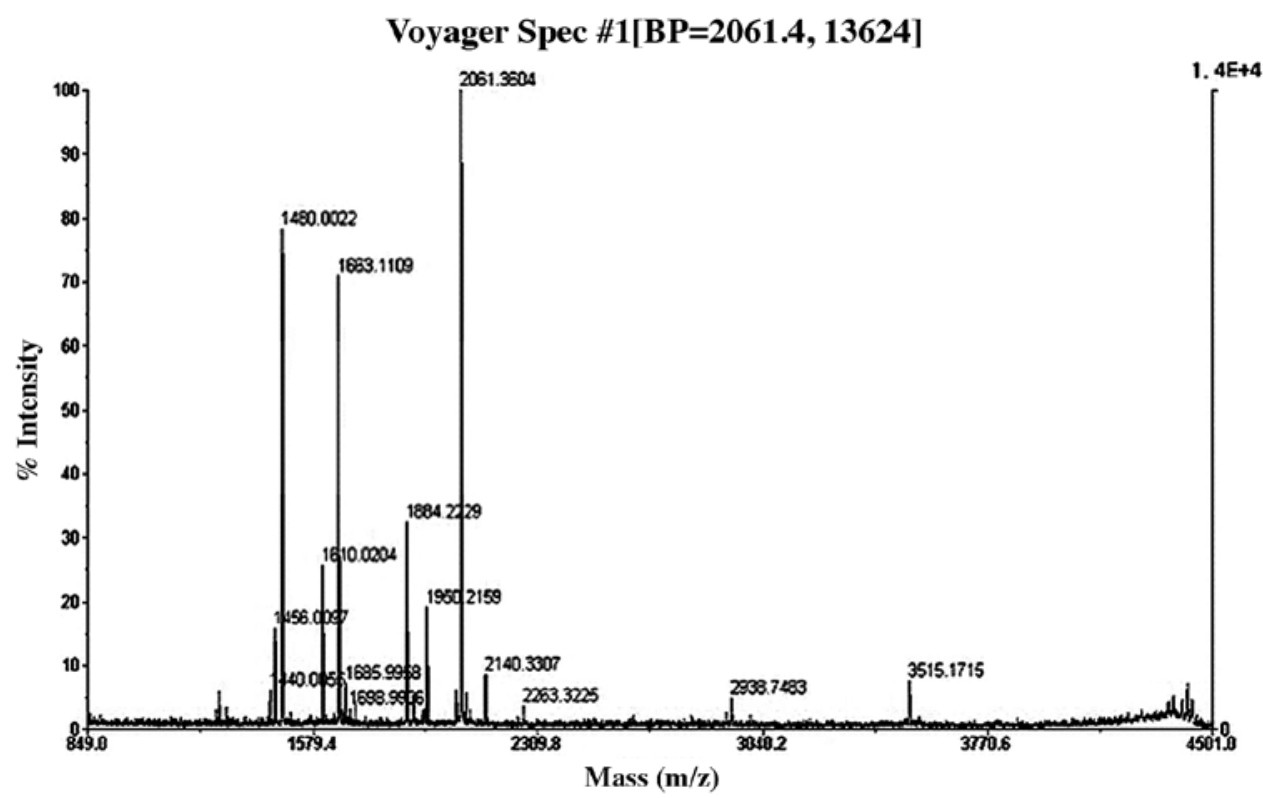

Figure 3. Peptide mass fingerprintings of protein spot 10 showing differential expression obtained by identification through MALDI-TOF-MS.

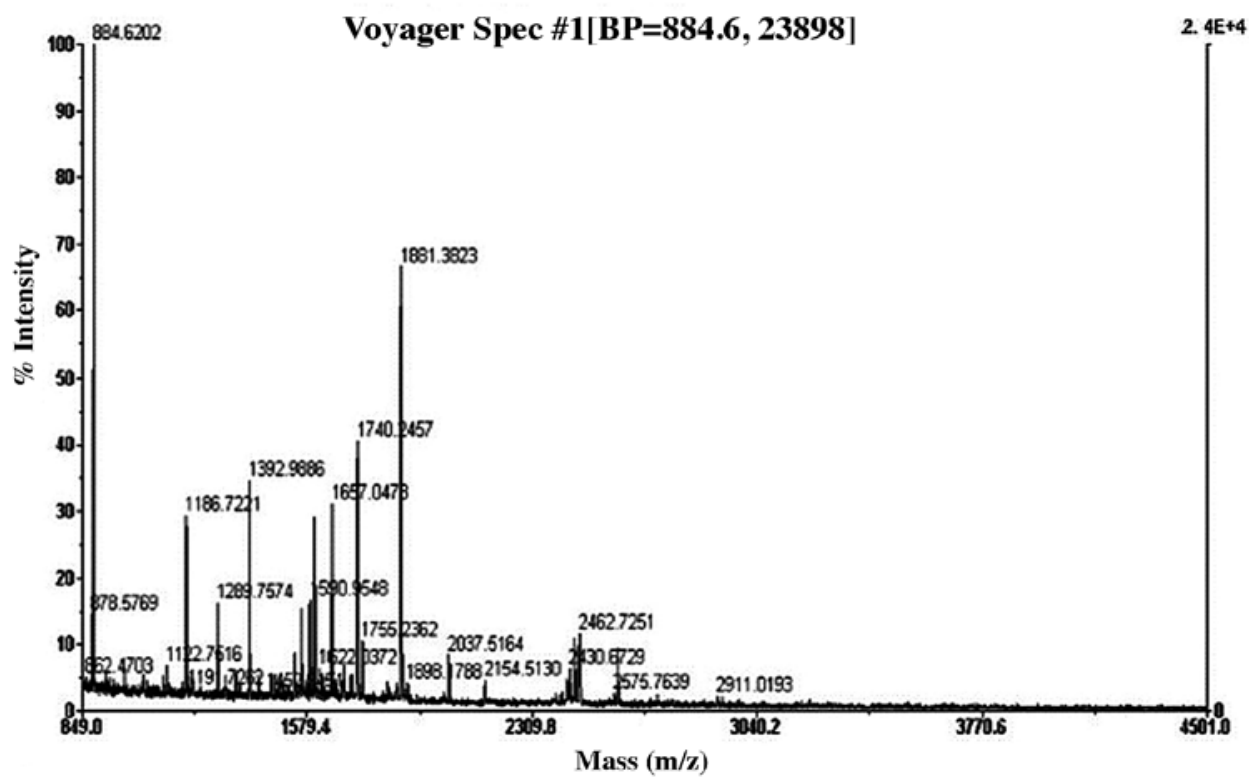

Figure 4. Peptide mass fingerprintings of protein spot 19 showing differential expression obtained by identification through MALDI-TOF-MS. 
Table II. The features of the 17 protein spots with the most prominent differential expression.

\begin{tabular}{rlrrrrrl}
\hline Spot & \multicolumn{1}{c}{$\begin{array}{c}\text { Database } \\
\text { ID }\end{array}$} & $\begin{array}{c}\text { Isoelectric } \\
\text { point }\end{array}$ & $\begin{array}{c}\text { Matching } \\
\text { peptides }\end{array}$ & $\begin{array}{c}\text { Molecular } \\
\text { weight }\end{array}$ & $\begin{array}{c}\text { Sequence } \\
\text { coverage (\%) }\end{array}$ & Score & \multicolumn{1}{c}{ Protein name } \\
\hline 2 & Q80WH8_9MU & 5.83 & 33 & 54058 & 72 & 269 & Type II cytoskeletal 8 \\
3 & RIQ61509 & 6.20 & 9 & 30212 & 39 & 100 & Elongation factor 2 (Fragment) \\
4 & Q4FZS2 & 6.36 & 19 & 37330 & 69 & 146 & Hypothetical protein \\
5 & Q566Q8 & 5.28 & 9 & 27647 & 40 & 86 & Basophilic leukemia expressed \\
& & & & & & & protein BLES03 \\
6 & JN0924 & 6.12 & 15 & 22865 & 73 & 185 & Heat shock 27 protein \\
7 & Q6PDU9 & 6.23 & 11 & 27703 & 50 & 75 & NADH dehydrogenase (ubiquinone) \\
& & & & & & & flavoprotein 2 \\
8 & ALDR & 6.28 & 13 & 36099 & 53 & 135 & Aldose reductase \\
10 & Q496Z5 & 5.32 & 47 & 53503 & 82 & 370 & Peripherin intermediate filament protein \\
11 & Q5DK8 & 6.43 & 39 & 39064 & 59 & 102 & NADH dehydrogenase Fe-S protein \\
12 & PPIA & 8.37 & 13 & 17960 & 66 & 123 & Peptidyl-prolyl cis-trans isomerase A \\
13 & AAB46848 & 6.14 & 14 & 15321 & 77 & 149 & Fatty acid-binding protein \\
14 & S54181 & 8.11 & 14 & 38233 & 52 & 89 & Stretch-binding protein CSBP \\
15 & A41015 & 8.17 & 14 & 47668 & 40 & 80 & Dihydrolipoamide S-succinyltransferase \\
17 & R6RTP2 & 4.44 & 9 & 11685 & 93 & 96 & Acidic ribosomal protein P2 \\
18 & APOA1_BOVIN & 5.71 & 13 & 30258 & 40 & 73 & ApolipoproteinA-I precursor \\
19 & Q8BPI0 & 5.20 & 13 & 22991 & 66 & 87 & Rho GDP dissociation inhibitor (GDI) $\alpha$ \\
20 & TVHUH & 5.16 & 12 & 21627 & 79 & 96 & Transforming protein p21 \\
\hline
\end{tabular}

Functional classification was performed for the preliminary identified differentially expressed proteins and the main types of proteins were divided into: i) cytoskeletal proteins: type II cytoskeletal 8 and peripherin intermediate filament protein; ii) basic metabolic enzymes: aldose reductase, peptidyl-prolyl cis-trans isomerase A, NADH dehydrogenase (ubiquinone) flavoprotein 2, NADH dehydrogenase (ubiquinone) Fe-S protein 1 , dihydrolipoamide $\mathrm{S}$-succinyltransferase; iii) molecular chaperone: heat shock protein 27 ; iv) signal transduction proteins RhoGDI $\alpha$, fatty acid-binding protein; v) cell proliferation and apoptosis-associated proteins: elongation factor 2 (fragment), dC stretch-binding protein; vi) proteins of unknown function, hypothetical proteins. The features of the 17 protein spots identified with the most prominent differential expression are summarized in Table II.

Decreased expression of RhoGDIa. The expession of RhoGDI $\alpha$ at different time points following treatment with NGF was examined by western blot analysis. Compared with the control group $(1.87 \pm 0.21)$, RhoGDI $\alpha$ protein expression in the adrenal medullary cells at 2 and 4 days following tretment with NGF continued to decrease $(1.26 \pm 0.15, \mathrm{P}<0.05$; $1.00 \pm 0.18, \mathrm{P}<0.01)$. However, no significant difference was noted in the RhoGDI $\alpha$ expression level between 4 and 6 days following treatment with NGF (Fig. 5A).

Peripherin expression increased at different time points following treatment with NGF. As shown by western blot analysis, compared with the control group $(0.81 \pm 0.07)$, peripherin expression in the adrenal medullary cells at 2 days following treatment with NGF $(1.25 \pm 0.11, \mathrm{P}<0.05)$ significantly increased, and there was no significant difference in peripherin protein expression after the 2-day time point (between 2 and 6 days (Fig. 5B).

\section{Discussion}

Chromaffin cells of the adrenal medulla are the precursor cells of sympathetic ganglion cells and adrenal medullary cells with 2 phenotypes, the endocrine and neuronal phenotype (12). The phenotype in normal target tissue is the endocrine phenotype. With the same origin of neurons, these cells have a potential capability to transform into neurons, apart from their endocrine function. The study proves that adrenal medullary cells undergo neuron-like changes following treatment with NGF, demonstrated by the change in their morphology, ultrastructure and endocrine function.

Following treatment with NGF, two-dimensional gel electrophoresis and mass spectrometry revealed that among the protein spots with the most prominent differential expression, 48 spots showed an upregulated expression and 37 spots showed a downregulated expression; no 'all-or-none' spots with significant differences in expression were found. Within the abovementioned scope, 14 protein spots with upregulated expression and 6 with downregulated expression were randomly selected for identification with MALDI-TOF-MS. The results revealed that 17 protein spots showed a prominent 
A
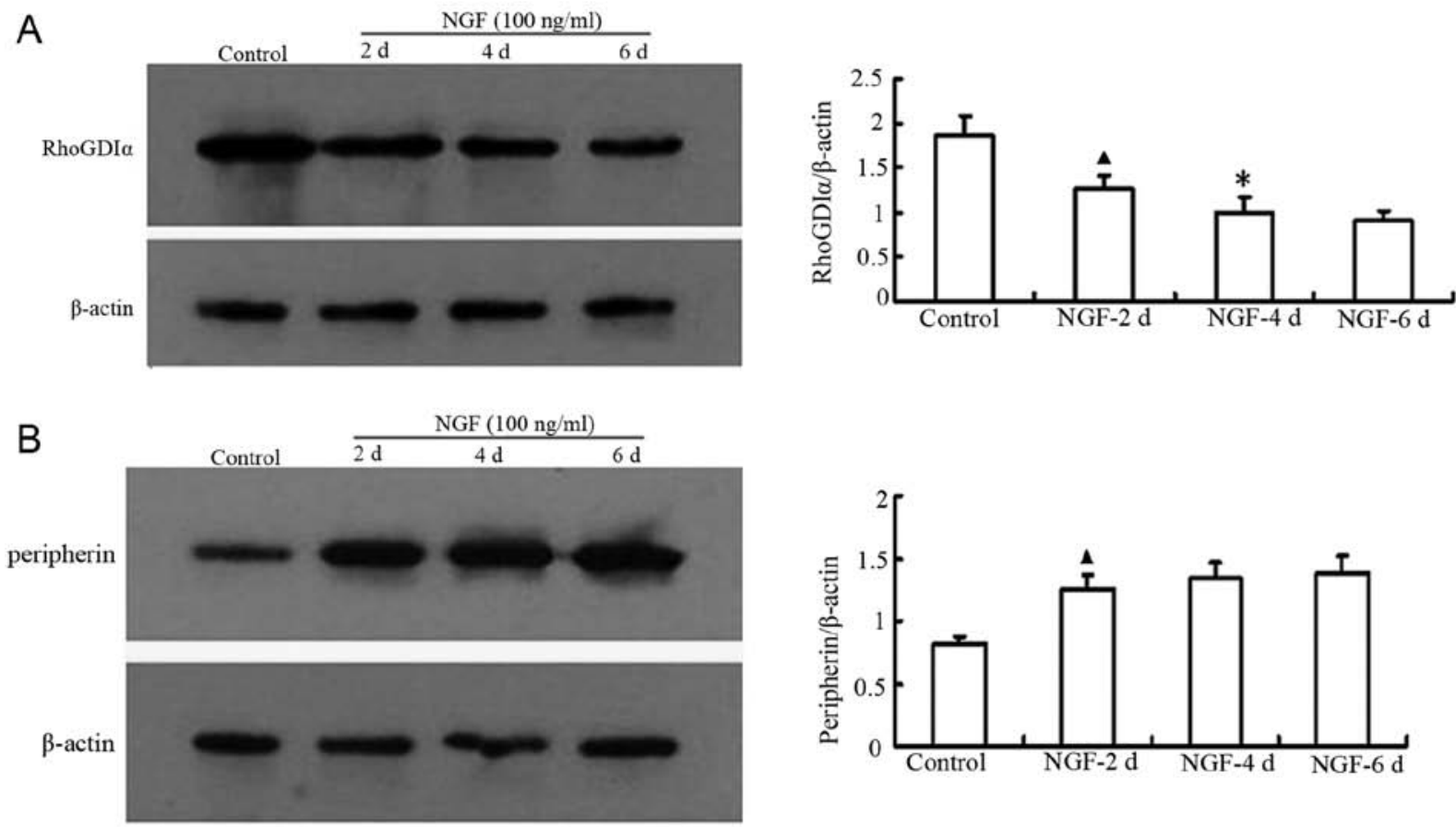

Figure 5. Verification of protein spots with differential expression levels by western blot analysis. (A) Effect of treatment with nerve growth factor (NGF) on RhoGDI $\alpha$ expression in adrenal medullary cells. The bars indicate the means $\pm \mathrm{SD}(\mathrm{n}=4) .{ }^{\wedge} \mathrm{P}<0.05$ vs. control; ${ }^{*} \mathrm{P}<0.01$ vs. control. (B) Effect of treatment with NGF on peripherin expression in the adrenal medullary cells by western blot analysis. The bars indicate the means \pm SD $(n=4) .{ }^{\wedge} \mathrm{P}<0.05$ vs. control, number of repetitions of the experiment.

differential expression. Peripherin and RhoGDI $\alpha$ may play a role in this process of differentiation.

Peripherin is not only a type III intermediate filament protein, but the most important intermediate filament protein in sympathetic neurons and PC12 cells. It is mainly involved in the constitution of the cytoskeleton, as well as the cell's internal and external information transmission and cell differentiation. It is expressed in some neurons of the developing or differentiated peripheral and central nervous system. The gene expression of peripherin has strict tissue specificity, but it can be transformed from one type to another in the main differentiation stages or under the influence of intrinsic and extrinsic factors. Previous studies have demonstrated that NGF induces the upregulation of the peripherin expression in $\mathrm{PC} 12$ cells and is involved in the process of axon growth and extension $(13,14)$. In the process of cell development, regeneration and differentiation, a significant increase in peripherin expression level is consistent with the time phase of the germination and growth of neural axons. As previously shown $(15,16), 12 \mathrm{~h}$ after the treatment of PC12 cells with NGF, peripherin expression was observed and $48 \mathrm{~h}$ later, peripherin expression levels began to increase this increase was maintained for a long time. On the contrary, if peripherin expression is intervened by peripherinsiRNA, it can obviously resist the germination, extension and maintainance (17) of cell axons. The results of the present study showed that the peripherin expression level in adrenal medullary cells was upregulated following treatment with NGF and western blot analysis verified that peripherin expression levels also increased, indicating that NGF induces an increase in neuronal cytoskeletal protein expression in adrenal medullary cells; thus, it can be hypothesized that the transformation of medullary cells to neurons may be the result of an increase in the expression of neuronal-specific peripherin induced by NGF.

Rho protein is one of the members of the Ras superfamily of guanosine triphosphatase (GTPase), which can generally exist in either an active or inactive state, that is, it will be activated if it combines with GTP and it will be inactivated if it combines with guanosine diphosphate (GDP) $(18,19)$. The active RhoGTP enzyme can combine with effector proteins, involved in the regulation of a series of important biological processes in cells, such as the regulation of gene transcription, cell transformation and the cytoskeleton. The regulation effect of GDIs is of the most important among the circulating regulatory factors of active and inactive Rho protein. Studies have shown that RhoGDI can, when used as a negative regulator, affect the growth regulation and transformation of cells by activating Rho-family members Cdc $42(20,21)$. RhoGDI $\alpha$ is an important regulatory factor for the maintenance of cell morphology and function. As the intracellular RhoGDI $\alpha$ expression level is almost equal to the total Rho protein expression levels (including RhoA, Rac and $\mathrm{Cdc} 42$, etc.), it may be presumed that all the RhoGDI $\alpha$ in cells can combine RhoGTPase (active or inactive status) and form complexes. Stimulated by endogenous and exogenous NGF, the reduction of total RhoGDI $\alpha$ expression levels in cells means that more and more Rho protein can be dissociated from complexes and be activated by guanine nucleotide exchange factors (GEFs), and then act on downstream effector molecules. The study by Li et al (23) showed that the obvious decrease in the RhoGDI expression level can relieve the inhibitory effects on endogenous Racl and protein molecules of other Rho family members, thus regulating the secretory function of chromaffin cells. Studies 
on vascular smooth muscle cells (VSMCs) have shown (24) that when cells undergo differentiation following endogenous and exogenous stimulation, RhoGDI $\alpha$ expression levels in cells significantly decrease accompanied by the obvious increase in the Rac expression level. Using siRNA-RhoGDI $\alpha$ to transfect VSMCs can upregulate h1-calponin (a type of smooth muscle cell-specific differentiation marker protein), while using siRNA-Rac to transfect VSMCs can downregulate h1-calponin. In the present study, we found that the RhoGDI $\alpha$ protein expression level in adrenal medullary cells decreased following treatment with NGF. Western blot analysis also verified the obvious decrease in RhoGDI $\alpha$ expression. We hypothesized that the downregulated expression of RhoGDI $\alpha$ may be associated with cell growth regulation, transformation and the formation of the cytoskeleton by releasing more Rho GTPase and transforming them into an activated form.

In conclusion, in this study, we isolated and identified a group of proteins with a significant change in expression in primary adrenal medullary cells treated with NGF by two-dimensional gel electrophoresis combined with mass spectrometry, and verified changes in peripherin and RhoGDI $\alpha$ protein expression by immunoblotting. These data revealed the key proteins that may lead to the changes in the biological behavior of adrenal medullary cells. Our results may provide an important basis and clues for the further investigation of the signal transduction mechanisms of the NGF-induced transdifferentiation of adrenal medullary cells.

\section{Acknowledgements}

This study was supported by grants from the National Natural Science Foundation of China (nos. 30960143 and 30570802).

\section{References}

1. Freund-Michel V and Frossard N: The nerve growth factor and its receptors in airway inflammatory diseases. Pharmacol Ther 117: $52-76,2008$.

2. Unsicker K, Huber K, Schütz G and Kalcheim C: The chromaffin cell and its development. Neurochem Res 30: 921-925, 2005.

3. Barreto-Estrada JL, Medina-Ortiz WE and Gareia-Arraras JE: The morphological and biochemical response of avian embryonic sympathoadrenal cells to nerve growth factor is developmentally regulated. Brain Res Dev Brain Res 144: 1-8, 2003.

4. Forander P, Broberger C and Stromberg I: Glial-cell-line-derived neurotrophic factor induces nerve fibre formation in primaly cultures of adrenal chromaffin cells. Cell Tissue Res 305: 43-51, 2001.

5. Wang J, Hu CP and Feng JT: Dysfunction of releasing adrenaline in asthmatic adrenaline medullary chromaffin cells due to functional redundancy primed by nerve growth factor. Zhonghua Jie He He Hu Xi Za Zhi 29: 812-815, 2006 (In Chinese).
6. Li QG, Wu XR, Li XZ, Yu J, Xia Y, Wang AP and Wang J: Neuralendocrine mechanisms of respiratory syncytial virus-associated asthma in a rat model. Genet Mol Res 11: 2780-2789, 2012.

7. Lillien LE and Claude R: Nerve growth factor is a mitogen for cultured chromaffin cells. Nature 317: 632-634, 1985.

8. Unsicker K, Zwarg U and Habura-Flüh O: Differentiation and transdifferentiation of adrenal chromaffin cells of the guinea pig. III. Transplants under the kidney capsule. Cell Tissue Res 229: 299-308, 1983.

9. Livett BG: Adrenal medullary chromaffin cells in vitro. Physiol Rev 64: 1103-1161, 1984.

10. Unsicker K and Muller TH: Purification of bovine adrenal chromaffin cells by differential plating. J Neurosci Methods 4: 227-241, 1981.

11. Koike T: A possible involvement of cytoplasmic $\mathrm{Ca}^{2+}$ in sodium dependency of neurite outgrowth of rat pheochromocytoma PC12 cells. Biochim Biophys Acta 763: 258-264, 1983.

12. Unsicker K, Krisch B, Otten U and Thoenen H: Nerve growth factor-induced fiber outgrowth from isolated rat adrenal chromaffin cells: impairment by glucocorticoids. Proc Natl Acad Sci USA 75: 3498-3502, 1978.

13. Aletta JM, Shelanski ML and Greene LA: Phosphorylation of the peripherin $58-\mathrm{kDa}$ neuronal intermediate filament protein. Regulation by nerve growth factor and other agents. J Biol Chem 264: 4619-4627, 1989.

14. Sterneck E, Kaplan DR and Johnson PF: Interleukin-6 induces expression of peripherin and cooperates with Trk receptor signaling to promote neuronal differentiation in PC12 cells. J Neuroehem 67: 1365-1374, 1996

15. Leonard DG, Gorham JD, Cole P, et al: A nerve growth factorregulated messenger RNA encodes a new intermediate filament protein. J Cell Biol 106: 181-193, 1988.

16. Troy CM, Greene LA and Shelanski ML: Neurite outgrowth in peripherin-depleted PC12 cells. J Cell Biol 117: 1085-1092, 1992.

17. Helfand BT, Mendez MG, Pugh J, et al: A role for intermediate filaments in determining and maintaining the shape of nerve cells. Mol Biol Cell 14: 5069-5081, 2003.

18. Sah VP, Seasholtz TM, Sagi SA and Brown JH: The role of Rho in $\mathrm{G}$ protein-coupled receptor signal transduction. Annu Rev Pharmacol Toxicol 40: 459-489, 2000

19. Meriane M, Mary S, Comunale F, et al: Cdc42Hs and Rac1 GTPases induce the collapse of the vimentin intermediate filament network. J Biol Chem 275: 33046-33052, 2000

20. Gibson RM, Gandhi PN, Tong X, et al: An activating mutant of Cdc42 that fails to interact with Rho GDP-dissociation inhibitor localizes to the plasma membrane and mediates actin reorganization. Exp Cell Res 301: 211-222, 2004.

21. Lin Q, Fuji RN, Yang W and Cerione RA: RhoGDI is required for Cdc42-mediated cellular transformation. Curr Biol 13: 1469-1479, 2003

22. Michaelson D, Silletti J, Murphy G, et al: Differential localization of Rho GTPases in live cells: regulation by hypervariable regions and RhoGDI binding. J Cell Biol 152: 111-126, 2001.

23. LI Q, Ho CS, Marineseu V, et al: Facilitation of $\mathrm{Ca}(2+)-$ dependent exocytosis by Rac1-GTPase in bovine chromaffin cells. J Physiol 550: 431-445, 2003.

24. Qu MJ,Liu B, Qi YX and Jiang ZL: Role of Rac and Rho-GDI alpha in the frequency-dependent expression of h1-calponin in vascular smooth muscle cells under cyclic mechanical strain. Ann Biomed Eng 36: 1481-1488, 2008. 